\title{
La leche y la sangre, el cuerpo y el espíritu: significaciones de lo corporal en La teta asustada, de Claudia Llosa*
}

\author{
Milk and Blood, Body and Spirit: Meanings of the Corporeal in La teta asustada by Claudia Llosa \\ Do leite e o sangue, o corpo e o espírito: significações do corporal em La teta asustada, de Claudia Llosa
}

\author{
José Enrique Finol ${ }^{\text {a }}$ \\ Universidad de Lima, Perú \\ jfinol@ulima.edu.pe \\ ORCID: https://orcid.org/0000-0001-9473-9751 \\ José Carlos Cabrejo \\ Universidad de Lima, Perú \\ ORCID: https://orcid.org/0000-0002-8388-4301
}

DOI: https://doi.org/10.11144/Javeriana.syp39-76.lsce

\section{Resumen:}

En este trabajo presentamos los resultados de una investigación sobre la película La teta asustada (2009), de la directora peruana Claudia Llosa. Se propone una aproximación novedosa al análisis e interpretación del film, de modo que puedan destacarse aspectos escasamente tratados en la bibliografía sobre el tema. Partimos del principio según el cual el cuerpo es el elemento fundamental en la semiotización del mundo, un aspecto que la película desarrolla extensa e intensamente. Se propone una clasificación compuesta por cinco tipos de corporalidades (espacial, temporal, sexual, vegetal y vital), las cuales configuran un sentido específico de la corporeidad, concepto entendido como el conjunto de los imaginarios asociados al cuerpo, en un contexto y momento histórico determinados.

Palabras clave: cuerpo, La teta asustada, corporalidad, corporeidad, espacio, tiempo.

\section{Abstract:}

This work shows the results from a research on the film La teta asustada (2009) by the Peruvian director Claudia Llosa. An innovative approach is proposed for the analysis and interpretation of the film in order to highlight some aspects barely dealt with in the previous bibliography on this topic. We start with a principle stating that the body is an essential element in the semiotization of the world, an aspect extensively and intensively developed in this film. A proposal consisting of five types of corporeity (spatial, temporal, sexual, vegetal and vital) is proposed. They shape a specific sense of corporeity, a concept understood as a set of imageries associated with the body in a specific context and historic time.

Keywords: body, La teta assustada, corporeity, space, tempo.

\section{Resumo:}

Neste trabalho apresentamos os resultados de pesquisa sobre o filme La teta asustada (2009), da diretora peruana Claudia Llosa. Propõe-se uma nova abordagem à análise e interpretação do filme, de modo a destacar aspectos escassamente tratados na bibliografia sobre o tema. Partimos do princípio segundo o qual o corpo é o elemento fundamental na semiotização do mundo, um aspecto que o filme desenvolve extensa e intensamente. Propõe-se uma classificação composta por cinco tipos de corporalidades (espacial, temporal, sexual, vegetal e vital), as quais configuram um sentido específico da corporeidade, concepto entendido como o conjunto dos imaginários associados ao corpo, em um contexto e momento histórico determinados.

Palavras-chave: corpo, La teta asustada, corporalidade, corporeidade, espaço, tempo.

La matière même du film est l'enregistrement d'une construction spatiale et d'expressions corporelles. Éric Rohmer (1958)

A mí me interesa mantener al espectador alerta y

Notas de autor

a Autor de correspondencia. Correo electrónico: jfinol@ulima.edu.pe 
ponerlo en guardia. (...); parte del efecto que busco con mis películas es colocar al espectador en una posición de descubrir, de tratar de leer más allá. Claudia Llosa (2010)

\section{Introducción}

Probablemente La teta asustada ${ }^{[1]}(2009)$ sea una de las películas latinoamericanas sobre la cual se haya realizado el mayor número de análisis e interpretaciones, entre ellas cabe mencionar los trabajos de Cabrejo (2009), Espinoza (2010), Knoester (2010), Lillo (2011), Varas (2012), Tapia 2013, Maseda (2014), Sagermann Bustinza (2014), Rueda (2015), Paredes Dávila (2015), Laura Atanacio (2015), Bedoya (2015), Salinas (2016), Rojas (2017), Bernales Albites y Gómez (2017). De modo que al proponer el siguiente análisis lo hacemos desde una perspectiva poco desarrollada previamente.

Si bien algunos autores mencionan la presencia y pertinencia de las significaciones del cuerpo en este film, premiado en 2009 en el festival de Cine de Berlín con el Oso de Oro a la mejor película, la bibliografía revisada nos muestra la ausencia de un análisis detallado, que desarrolle la hipótesis según la cual el cuerpo es uno de los estructurantes fundamentales de la organización semiótica del film. Entre los autores que han señalado la pertinencia de las significaciones del cuerpo en La teta asustada, están Cabrejo (2009), Tapia (2013), Laura Atanacio (2015) y Bedoya (2015). El primero ha señalado la dialéctica entre lo masculino y lo femenino y la imposibilidad de Fausta, personaje principal, "de relacionarse eróticamente con el sexo opuesto"; además, "la relación de la protagonista con su madre muerta (es) un cordón umbilical invisible, difícil de cortar y que termina mostrando a la presencia masculina como otro cuerpo, extraño, incomprensible, amenazante" (Cabrejo, 2009, p. 47).

Para Tapia, en un análisis basado en los conceptos de Homo sacer, de Agamben y Heller-Roazen (1998), y fuera de plano, de Lauretis (1996), la película es una "representación del cuerpo desechable" (2013, p. 61). Laura Atanacio, en una comparación entre Fausta y Madeinusa, personaje de la película homónima de la misma directora, realiza un análisis de las representaciones del cuerpo a través de diversos planos cinematográficos. Por su parte, Bedoya, quien la analiza siguiendo el modelo secuencial de los ritos de paso, señala que para el personaje principal "el mundo se mueve a gran velocidad, pero Fausta se niega a participar en él porque su cuerpo rechaza cualquier roce o contacto con el medio. Las manos contraídas de Magaly Solier son la expresión visual del dolor enraizado: son manos contraídas y nudosas como papas" (2015, p. 120. Cursivas nuestras).

Para nuestro análisis, nos proponemos elaborar un modelo de las representaciones del cuerpo que se desarrollan a lo largo de la película y presentar las vinculaciones de tales representaciones con el contexto histórico-cultural, de modo que estas recuperen el sentido que solo esos contextos pueden dar a plenitud. Quizás, lo primero que habría que decir de La teta asustada es que se trata un texto donde predominan los símbolos y los sentidos insinuados, sugeridos, gracias a significantes abiertos para que el espectador y el analista los descubran y descifren. Esa es una de las razones de la variedad de interpretaciones y asociaciones que la película promueve y que dificultan establecer su sentido general, prevalente, cuyo acotamiento requiere operaciones heurísticas que permitan determinar sus redundancias, sus énfasis y, de allí, las isotopías ${ }^{[2]}$ que la estructuran.

\section{Corporeidad y corporalidades}

Según la hipótesis que desarrollaremos, en La teta asustada el cuerpo aparece como un componente estructurante de sus procesos de significación; en él, se articulan y expresan las visiones e isotopías que 
progresivamente modulan todo el entramado semiótico del film; un microuniverso coherente que, en medio de varias interpretaciones posibles, le da inteligibilidad. Según esta hipótesis, ese microuniverso se articula en un conjunto de corporalidades que, a su vez, a un nivel más complejo, componen lo que se ha definido como corporeidad (Finol, 2015, 2016). Se trata, en fin de cuentas, de entender y expresar el mundo a través del cuerpo, casi del mismo modo en que a menudo hablamos del mundo gracias a metáforas corporales. Proponemos dividir las corporalidades representadas en el texto fílmico en dos grandes categorías que llamaremos cualitativas y morfológicas. Las primeras son de carácter espacial y temporal, mientras que las segundas se subdividen en sexual, vegetal y vital.

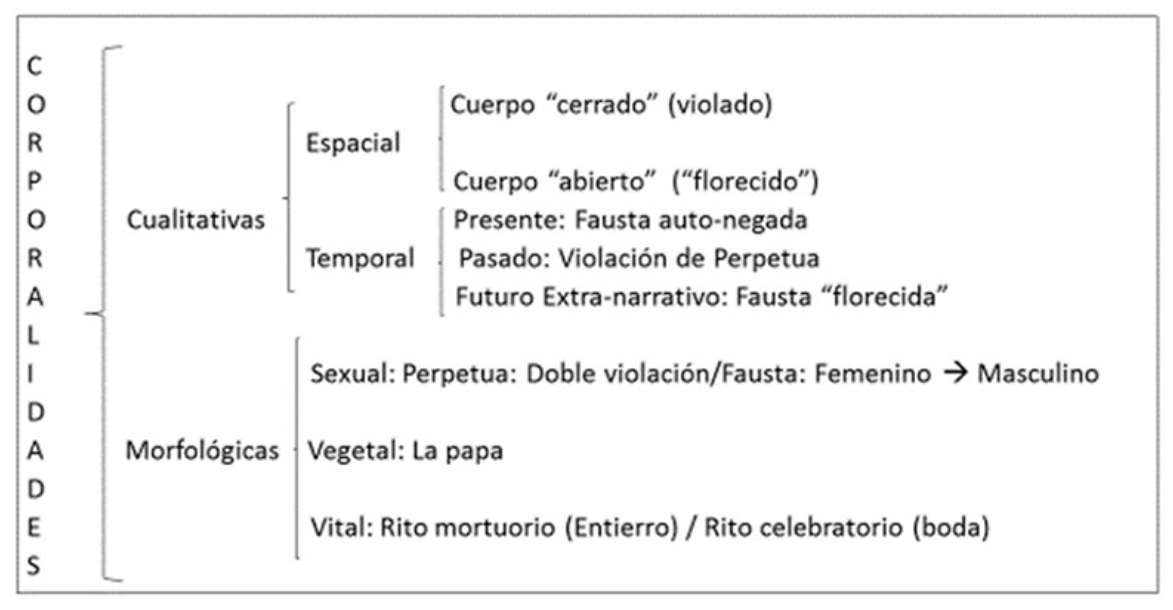

FIGURA 1.

Corporalidades cualitativas y morfológicas en La teta asustada (Llosa, 2009).

Fuente: elaboración propia.

Esas corporalidades se superponen, homogéneamente, en el texto; se entrelazan en un tejido lleno de símbolos, a veces equívocos o ambiguos, que la autora insinúa para provocar al espectador y liberar sus capacidades interpretativas, un propósito en el que la directora insiste:

Cada imagen se potenció hasta tal punto que cada una vale por sí misma, y permite que el espectador la recorra desde su propia experiencia de vida [...] es utilizar todo aquel plano sensible para que cada persona que ve la película la entienda a su modo [...] dependiendo del background, de los conocimientos de cada espectador se valorará a la película de distinta forma. Lo importante para mí es que la película se abra a una multiplicidad de lecturas. (Bedoya y Cabrejo, 2009, p. 54-55).

Es un propósito que, con otras palabras, ella ratifica en otra entrevista posterior: “[...] sí, me interesó crear espejos y prismas de rebote, para que cada persona la complete a su modo" (Chauca et al., 2010, p. 50).

\section{Corporalidades cualitativas}

Llamaremos corporalidades cualitativas a aquellas que se expresan en las relaciones que el cuerpo construye con el tiempo y el espacio.

1. Desde el punto de vista de la temporalidad ${ }^{[3]}$, la película se sitúa en un presente corporal narrativo en el cual Fausta vive su historia. Sin embargo, también Perpetua relata un tiempo pasado, en el cual se sitúa el origen del presente que la película desplegará, y desde el cual abrirá, simbólicamente, una ventana al futuro extranarrativo, este último representado en la maceta de flores que Fausta recibe y que cierra el último plano de la película. El tiempo pasado se expresa en el canto de Perpetua, la madre de Fausta, quien desde su cama relata la violación de la que había sido víctima cuando estaba embarazada de esta última. 
Quizás algún día tú sepas comprender lo que lloré, lo que imploré de rodillas a esos hijos de perra. Esa noche gritaba, los cerros remedaban y la gente reía. Con mi dolor luché diciendo: "A ti te habrá parido una perra con rabia... Por eso le has comido tú sus senos. Ahora pues, trágame a mí. Ahora pues, chúpame a mí, como a tu madre”. A esta mujer que les canta, esa noche le agarraron, le violaron. No les dio pena de mi hija no nacida. No les dio vergüenza. Esa noche me agarraron, me violaron con su pene y con su mano. No les dio pena que mi hija les viera desde dentro. Y no contentos con eso, me han hecho tragar el pene muerto de mi marido Josefo. Su pobre pene muerto sazonado con pólvora. Con ese dolor gritaba: "Mejor mátame y entiérrame con mi Josefo. No conozco nada de aquí”. (Llosa, 2009)

El cuerpo de Perpetua, acostado, inmóvil y con los ojos cerrados, es no solo el cuerpo violado, sino también es, en segundo lugar, el cuerpo que recuerda; es, así mismo, en tercer lugar, un cuerpo agonizante: se trata de una densa corporalidad que encarna la memoria violenta del pasado y también la muerte en el presente. De este modo, en su inicio, el film plantea una estructura temporal encarnada y expresada en el cuerpo de Perpetua, objeto de violación, dispositivo de memoria y muerte. Ese cuerpo, después de su tránsito de vida $\rightarrow$ muerte, como se verá en el resto del film, mantendrá encarnados esos valores semióticos y esa visión de la corporalidad; se trata de un cuerpo omnipresente a lo largo de la película que, como dice Bedoya (2015), también puede analizarse como un largo rito de paso, con sus etapas de separación, liminalidad y reincorporación. Pero, mientras el cuerpo muerto de Perpetua, un nombre con claras resonancias temporales, transita de principio a fin como una transformación que va de la vida, en las escenas iniciales, a la muerte y entierro, en las escenas finales, también Fausta transita de una muerte simbólica, expresada en su negación a la vida sexual y a la vida social y familiar, a una vida futura que la película simboliza gracias a un recurso simbólico de carácter vegetal.

Perpetua: vida $\rightarrow$ entierro $\rightarrow$ muerte

Fausta: muerte $\rightarrow$ florecimiento ${ }^{[4]} \rightarrow$ vida

2) En su estructura espacial, La teta asustada despliega cuatro polos generales que podríamos llamar doméstico y urbano, costa y sierra:

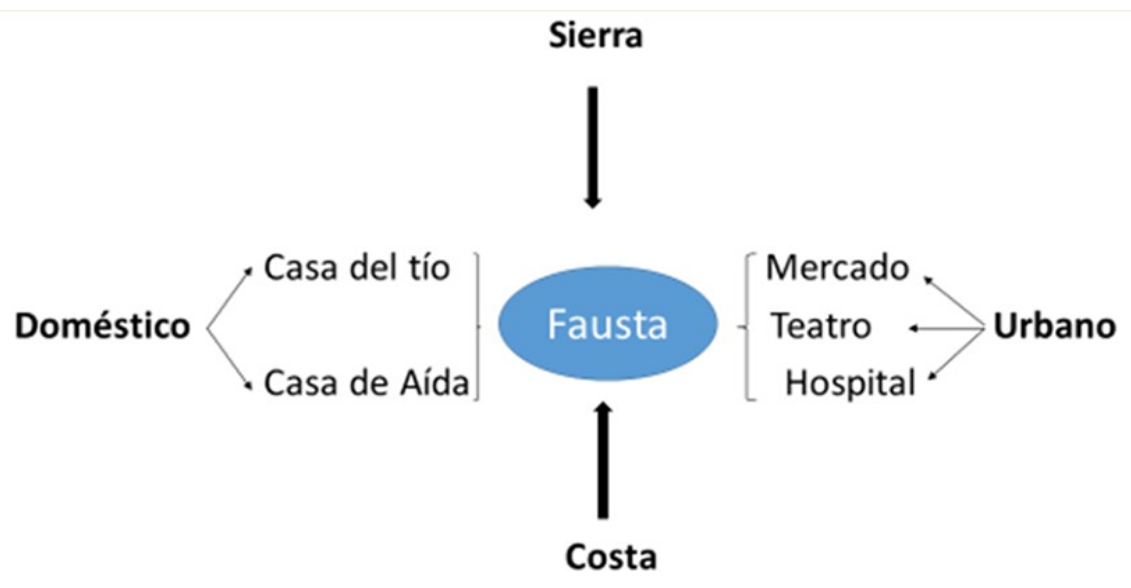

FIGURA 2.

Estructura espacial general.

Fuente: elaboración propia.

Es en la conjunción dialéctica entre estos cuatro polos espaciales, cada uno con sus disposiciones semióticas propias, donde ocurre la transformación corporal de Fausta que, inicialmente, parte de un paralelo con su madre, pues esta, gracias al síndrome de la teta asustada, la ha hecho parte de la violencia sufrida. Para reproducir y fortalecer ese paralelismo actorial entre Fausta y Perpetua, el film utiliza una recurrencia de carácter espacial, ya que, así como Perpetua es un personaje que apela a un tránsito que va de un espacio 
cerrado (la casa) a un espacio abierto (el mar), Fausta también es un cuerpo en clausura que recorre un camino narrativo que va de los espacios intrauterinos cerrados a un espacio abierto, una vez que permite que la papa sea extraída de su vagina. Como afirma Laura Atanacio, "Llosa emplea la papa de forma simbólica para colocar la sexualidad de Fausta en paréntesis, suspendida: nada sale, ni nada entra de su cuerpo" (2015, p. 72). Sin embargo, mientras en el caso de Perpetua la decantación por la muerte tiene un carácter telúrico, en el caso de su hija tiene un carácter vegetal, no solo por la papa que crece en su vagina, sino también por la simbolización construida a través de la flor que recibe al final.

Pero también el cuerpo de Perpetua será el dispositivo que marca buena parte de la estructura espacial de la historia, la cual, justamente, se inicia en un espacio cerrado, la habitación donde reposa en una cama y, luego de su muerte y de ser embalsamada, es colocada debajo de la misma cama. Esa breve transición espacial del cuerpo de Perpetua es también la transición de la vida a la muerte, un ciclo que se completará en el mar y no, como podría esperarse, en la sierra. Cuando Fausta le pide a su madre muerta que vea el mar, subvierte el orden espacial esperado, pues ese cuerpo materno "pertenecía" a otro espacio, a su propia tierra. ¿Qué significa esa subversión? La directora y guionista, Claudia Llosa, ha dicho que:

En ese momento final, cuando Fausta entierra a su madre, ella representando los Andes y la playa representando la costa, le dice: 'Mira el mar mamá. No vale únicamente que la costa mire a la sierra, también tiene que darse el opuesto: la sierra tiene que mirar a la costa. El acercamiento debe ser de ambos lados. (Chauca et al., 2010, p. 52)

En nuestra lectura, el mar representa para el cuerpo sufrido y yerto de Perpetua una ruptura, la liberación definitiva de sus sufrimientos, la apertura a otros espacios donde la pesada carga telúrica de su violación y sufrimiento ya no existirá más. "El entierro de la madre en la orilla del mar, en un lugar completamente ajeno al área andina de donde proviene la familia, obedece en Fausta más que a una decisión de orden tradicional, a un rompimiento con la parte nociva de su experiencia andina" (Salinas, 2016, p. 121). Este quiebre narrativo que va de lo telúrico a lo marino, de la prisión a la libertad, de la muerte a la vida ha sido bien explicado por Bedoya cuando afirma:

Fausta transita entre dos órdenes de elementos naturales antagónicos, pero imbricados: la "tierra” y el “agua”. En vía de superar el apego arcaico a la madre, [...] corta la vinculación mórbida con la tierra, [...] para acceder al florecimiento personal, la afirmación de su capacidad creadora y el ejercicio de su sexualidad en el orden abierto del "aire" y del "mar". (Llosa, 2010, p. 148)

Siguiendo lo expresado por Bedoya, Perpetua es la representación como sinécdoque de algo mayor, de la "Pachamama" "5], de la "madre tierra" vejada, mientras que Fausta escapa, al final, hacia un orden líquido, marino. Antes que una confluencia entre costa y sierra, el film nos presenta la ruptura espacial del paralelismo madre-hija: se trata, en cierto modo, de la bifurcación de sus caminos, una bifurcación narrativamente necesaria para el propósito "optimista" del mensaje fílmico. En esta escena frente al mar, mientras el cuerpo materno regresa a la tierra, pero frente al mar, el cuerpo filial inicia su camino hacia su restitución vital. Esa visión del mar contradice su tradicional carácter simbólico, pues como lo señala Cirlot, el mar, "los océanos, se consideran así como la fuente de la vida y el final de la misma. 'Volver al mar' es como 'retornar a la madre', morir" (1992, p. 298). En la película, el mar significa más bien un renacimiento, una vez que se convierte en objeto de mirada de Fausta al lado del cuerpo de la madre. Mar y tierra se convierten en unidad que abre paso a una nueva etapa en la vida del personaje interpretado por Magaly Solier.

En términos semióticos, entre las isotopías extremas de vida y muerte, el film desarrolla con mayor fuerza los recorridos narrativos que privilegian la primera; lo que recurrentemente también permea la estructura actorial, al privilegiar el programa narrativo de Fausta sobre el de Perpetua. El dispositivo se extiende a las corporalidades en juego: sobre el cuerpo de la memoria y la muerte, sobre el cuerpo violentado y humillado de Perpetua, prevalece el cuerpo redimido y liberado de Fausta, quien logra vencer los llakis ${ }^{[6]}$ heredados de su madre y "su vínculo estrecho con la locura y con la muerte" (Theidon, 2004, p. 65). 
El paralelismo inaugural entre Fausta y Perpetua, madre e hija, cuerpos de un cuerpo inicial, se da gracias a la memoria de la violencia que ellas comparten; se trata de un paralelismo que solo se rompe cuando la primera sepulta a la segunda, lo que conduce al florecimiento simbólico de Fausta.

\section{Corporalidades morfológicas}

1) Lo que llamamos corporalidad sexual lo encontramos, desde el inicio, en la propia narración cantada que hace Perpetua, en la cual cuenta cómo fue doblemente violada, pues además de su agresión corporal, vaginal, también es obligada a comer el pene muerto de su marido: "Y no contentos con eso, me han hecho tragar el pene muerto de mi marido Josefo. Su pobre pene muerto sazonado con pólvora”. Se trata de una introducción brutal que ubica al cuerpo y su violencia sexual en el centro del relato.

La papa que Fausta ha colocado en su vagina, como un escudo defensivo frente a la violencia machista, es también un símbolo sexual, como bien señala Cabrejo: “en el lenguaje coloquial, la 'papa' es una manera de referirse a la zona sexual de la mujer” (2009, p. 48). Además, la papa es una suerte de cinturón de castidad, un "escudo de guerra [...] porque solo el asco detiene a los asquerosos", como ella misma los llama; el tubérculo es asumido ya no como vocación, sino como defensa del cuerpo, lo que trae aparejada su autonegación erótica y sexual.

La referencia al asco nos lleva a comprender cómo en el personaje de Fausta se introduce lo que Kristeva refiere como la abyección, que implica "una de esas violentas y oscuras rebeliones contra aquello que lo amenaza y que le parece venir de un afuera o de un adentro exorbitante, arrojado al lado de lo posible y de lo tolerable, de lo pensable" (Kristeva, 1988, p. 7). Según la autora, la abyección "perturba una identidad, un sistema, un orden. Aquello que no respeta los límites, los lugares, las reglas... es inmoral, tenebrosa, amiga de rodeos, turbia" (p. 11). El asco es parte esencial de lo abyecto. En ese sentido, la suciedad corporal que se forma al interior de la vagina de Fausta es especular. El orden, la ley, la regla que enfrenta la protagonista son vistos como lo masculino y capaz de ser asquiento de una forma extremadamente perversa. El tubérculo que se guarda y se descompone en su interior como un desecho es un espejo de la propia suciedad que el sistema referido por Kristeva puede dejar a su paso, y que violentó terriblemente a su madre a través de las Fuerzas Armadas.

Por ello, en su autonegación, producto de los llakis que su madre le transmitiera a través de la leche materna, Fausta "termina mostrando la presencia masculina como otro cuerpo, extraño, incomprensible, amenazante" (Cabrejo, 2009, p. 46). Es justamente a la corporalidad sexual masculina a la que Fausta teme, de la que huye e intenta protegerse; ella desconfía del joven que en la fiesta trata de cortejarla y que luego, incluso, la busca en el lugar donde trabaja; desconfía de Noé, el jardinero, a quien exige una prueba de ser quien dice ser y cuyos caramelos rechaza; desconfía hasta de su propio tío, a quien cree capaz de querer enterrar el cuerpo de su madre en el patio de la casa donde viven. Sin embargo, es este último quien le tapa la nariz y la boca y en un simulacro de asfixia, mientras ella se ahoga, la conmina a la vida y a su "florecimiento": " $i$ Tú quieres vivir, pero no te atreves! ¡Ves como respiras! ¡Ves que quieres vivir!”. Esta escena, de un intenso significado en la trama narrativa, es el comienzo de la transformación de Fausta, del vencimiento de sus temores, de su apertura corporal al mundo.

Pero la desconfianza de mayor tensión narrativa es la que Fausta muestra hacia el jardinero. Después del encuadre donde ella sostiene en una mano los caramelos que él le ha regalado, aparece otro encuadre en ángulo picado de las piernas de Fausta, con falda, pero con un pantalón azul de hombre que cae alrededor de una de sus piernas, lo que sugiere que el personaje interpretado por Magaly Solier posee una dimensión femenina y otra masculina. Ello entra en consonancia con lo afirmado por Bachelard (2013) a propósito de la oposición entre animus y anima que hace Jung: 
Para que no hubiese confusión con las realidades de la psicología de superficie, C. G. Jung tuvo la feliz idea de poner el masculino y el femenino de las profundidades bajo el doble signo de dos sustantivos latinos: animus y anima. Son necesarios dos sustantivos para una sola alma a fin de transmitir la realidad del psiquismo humano. El hombre más viril, demasiado simplemente caracterizado por un animus fuerte, tiene también un anima, un anima que puede poseer manifestaciones paradojales. De igual modo, la mujer más femenina tiene también determinaciones psíquicas que prueban en ella la existencia de un animus. La vida social moderna, con su competencia que \#mezcla los géneros\#, nos enseña a refrenar las manifestaciones de la androginia. (Bachelard, 2013, p. 98)

Desde ese punto de vista, esa imagen del pantalón que desciende envolviendo una de las piernas de Fausta significa que en ella no solo está presente el anima, lo femenino, sino también el animus, lo masculino. Así, la protagonista de La teta asustada recuerda a Rebis, ser mitológico de aparición frecuente en grabados de alquimia caracterizado por tener una apariencia mitad hombre y mitad mujer. Dios lo dividió para que ambas mitades pudieran reproducirse. En ese sentido, la condición de Fausta es la de un Rebis metafórico, pero que a diferencia refleja la presencia conflictiva de lo masculino en su femineidad, que debe ser separada para abrirse a lo sexual. El animusy el anima presentes en ella conforman una tensión por resolver.

2) Asimismo, la corporalidad vital se expresa en el encuentro de dos formas rituales aparentemente contradictorias: por un lado, mientras Fausta se esfuerza por cumplir los ritos mortuorios que honrarán a su madre muerta y la harán reposar en su destino final, su prima Máxima se esfuerza por preparar y llevar a cabo los ritos matrimoniales; mientras en los primeros predominan los símbolos mortuorios y funerarios, como el embalsamado y el ataúd, en el segundo predominan los símbolos propios de la ritualidad festiva y su simbología de vida y reproducción; mientras Fausta se reclama de la cultura y la tradición andina, Máxima se reclama de la cultura popular, marginal, de la urbe limeña. Ambos ritos de paso, el funerario y el celebratorio, encierran en sus extremos la tensión cultural entre costa y sierra, pero esa tensión se resuelve en dos opciones narrativas distintas. La escena de celebración matrimonial que, curiosamente, sí expone el cruce cultural entre lo citadino y lo rural es la que muestra la actividad carnavalesca conocida como yunza. Según Álvarez Vita, esta consiste "en cortar un árbol íntegro, de más de cuatro metros de altura para plantarlo en un descampado, adornarlo multicolormente y volverlo a tumbar entre música y danzas” (1990, p. 552). Esta práctica, también conocida como "cortapalo" o "tumbamonte", es originalmente andina, pero por la migración también se realiza en Lima e incluso por peruanos que se encuentran en otros países, y posee en algunos casos una simbología particular: "La cosmovisión andina simboliza de manera sexual al árbol como el hombre y a la tierra como la mujer. En ese sentido, la penetración del palo hacia el suelo es rendirle tributo a la Mama Pacha (madre tierra). Por ello, va más allá de una celebración de amigos, sino de una fiesta a la tierra, donde después podamos obtener toda su energía a lo largo del resto del año" (Satélite, 2018).

Llama la atención que la escena de la yunza es previa a aquella en que Fausta se encuentra con el cuerpo de su madre frente al mar. Así, la caída del árbol también puede leerse como la pérdida en Fausta del animus perturbador e interno, de su disfórica dimensión masculina, lo que permite a la protagonista abrirse a la presencia masculina exterior y eufórica.

En la ya referida tensionalidad entre cultura tradicional indígena y cultura popular urbana, interviene luego la cultura de élite, clásica, representada por la presencia de Aída, la pianista frustrada; para que Fausta pueda rebasar los límites y fronteras entre su propia cultura y la de Aída debe pasar un detallado examen corporal (orejas, boca, pelo, dientes cuello, manos, etc.); debe bañar y desodorizar su cuerpo. Luego, para permanecer en esa cultura, debe entregar las melodías de sus cantos ${ }^{[7]}$ a cambio de regalos.

3) Las corporalidades sexual y vital están representadas en la fuerte presencia de los densos símbolos vegetales que se repiten en varias secuencias y que, incluso, recorren toda la obra. En una escena, Fausta aparece con una flor roja que casi cubre su rostro, un claro símbolo de pasión y deseo que, sin embargo, ella deja caer porque aún no asume a plenitud su propio cuerpo. Por otra parte, desde el punto de vista espacial, hemos visto el frondoso jardín de la casa de Aída y, desde el punto de vista actorial, hemos visto a un jardinero, cuyo papel en el florecimiento de Fausta es complementario del que cumple su tío. Cuando esta última le pregunta al jardinero por qué no siembra papas, este le dice que es una planta barata y que "florece poco", una metáfora 
vegetal con la que descalifica la papa en la vagina de Fausta y, por extensión, a su propio cuerpo. Sin duda, si consideramos el cuerpo de Fausta como dotado de una corporalidad vegetal, esto se debe, principalmente, a la papa que lleva en su vagina y que comienza a desarrollarse y a adueñarse de su cuerpo, por lo que ella se ve obligada a podarla; sin embargo, la papa lo infecta y lo controla, lo que se expresa en sus continuos desmayos. Es, no obstante, la trasmutación de ese símbolo, de negador de la sexualidad del cuerpo a liberador de la misma, lo que el filme desarrolla. En efecto, si la papa niega, reprime e impide la realización de la corporalidad sexual de Fausta, al final es esa misma planta la que va a representar su afirmación y liberación, o, como dice Llosa, "florecimiento"; se cumple así lo que dice el jardinero: "Las plantas dicen la verdad. No son como la gente".

En este sentido, la papa se convierte en un supersigno ${ }^{[8]}$, capaz de subsumir, con una enorme densidad semiótica, el sentido general de tiempos, actores y espacios. Si bien la semiótica de Greimas incluiría a este objeto vegetal en la categoría de actores, ya que, en cierto modo, también desarrolla un programa narrativo, nosotros creemos que los objetos deben clasificarse como un dominio aparte, en virtud de que ellos aportan contenidos más allá de lo que son los objetos de deseo. Ciertamente, la papa no es aquí lo que Greimas y Courtés (1979) llaman "objeto de valor". Visto así, en La teta asustada, la papa adquiere particulares dimensiones semióticas, pues condensa un sentido definitivo en la inteligibilidad del texto fílmico. El uso que Fausta hace de este vegetal contrasta con la peladura del mismo hecha por su prima Máxima ante la familia del novio, una prueba calificante, evidencia de sus habilidades y capacidades para ser una buena esposa, ya que logra pelar toda la papa sin que la concha se rompa.

Las corporalidades analizadas constituyen una corporeidad donde se integran diversos imaginarios que crean líneas de lectura, de análisis e interpretación del texto fílmico. Se trata de una corporeidad caracterizada por la memoria y la conflictividad, por la tristeza y la angustia, por la vitalidad y la muerte; no obstante, a pesar de todo, se trata de una corporeidad que encarna, en su escena final, el florecimiento, la prevalencia de la vida.

\section{El cuerpo-envoltura}

Fontanille (2008) propone una clasificación icónica del cuerpo: cuerpo-cavidad, cuerpo-envoltura, cuerpocarne y cuerpo-punto. De esos términos, nos parece útil recuperar el de cuerpo-envoltura, que plantea, por un lado, un cuerpo con una superficie hacia el exterior, y por otro, un cuerpo como continente, que cobija por lo tanto un contenido. Parte del acercamiento al cuerpo en La teta asustada no está necesariamente en su representación visual, sino en su representación verbal. El inicio en el que se escucha el canto de Perpetua y describe las atrocidades que sufrió su cuerpo, se le ve en primer plano. No vemos, sin embargo, lo que queda de ese cuerpo violentado. Está fuera de campo.

El cuerpo de Perpetua es un cuerpo-envoltura. Según Fontanille, dicho cuerpo se caracteriza por una "red polisensorial y superficial que pone en contacto el Mí [la carne] y el mundo, o más precisamente, que recibe, de un lado, solicitaciones del mundo y, del otro, solicitaciones del Mí" (2008, p. 192). Como superficie, el cuerpo-envoltura puede deformarse y tiene dos caras: "una cara vuelta hacia el contenido (el continente) y otra cara vuelta hacia el otro plano (la superficie de inscripción). Llegamos así a la representación de la siguiente función semiótica: 


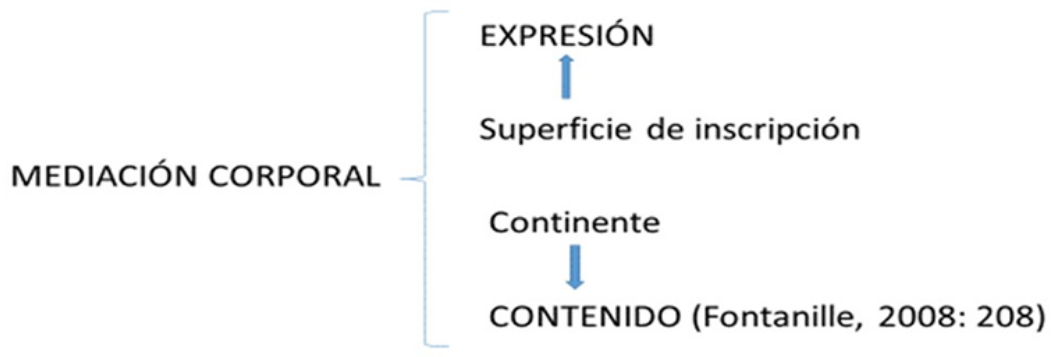

FIGURA 3.

La mediación corporal.

Fuente: Fontanille (2008, p. 208).

En el canto, el cuerpo de la madre de Fausta es superficie en la que se inscriben vaginal y oralmente figuras masculinas intrusivas, negativas, disfóricas: la mano y el pene violatorios, o el miembro viril muerto, cubierto de pólvora, del marido. Por el contrario, dicho cuerpo como continente resguarda un contenido femenino, la hija por nacer que ve desde el interior la agresión a Perpetua. Por lo tanto, la carne, el Mí, es femenino, consiste en la unión umbilical entre la madre y el feto, y el mundo exterior es uno masculino, que lo agrede; lo que Fausta, cantando, confirma: "yo lo vi todo desde tu vientre, sentí tu desgarro". Es verdad que Fausta señala que vio todo desde el vientre, pero la película sugiere como si Fausta siguiera presa de ese cuerpo-envoltura, solo que se refleja como un peso: el peso del cuerpo de la madre que no puede enterrar y el peso de la papa introducida en la vagina. Eventualmente, la papa, al conectarse con la tierra, se asocia con el concepto andino de Pachamama (madre tierra). Por lo tanto, esa maternidad terrenal está conectada con su vagina, es una ligazón maternal que el personaje tiene que cortar para su liberación sexual.

Lo mismo se observa en su relación con otro personaje femenino: Aida. Ella vive al interior de esa casa grande, casi silente, protegido del exterior, sumamente ruidoso y del que aparecen personajes masculinos que pretenden románticamente a Fausta. Es un espacio también de orden femenino (como el cuerpo de Perpetua) en el que Fausta está "presa" buscando conseguir las perlas prometidas a cambio de su "canto de sirena". En esa ruta de liberación incluso Fausta se convierte en cuerpo-envoltura cuando le dice al cadáver de su mamá que la llevará cargada "como a un bebé".

Los cuerpos en La teta asustada en tanto cuerpos-envolturas funcionan, además, como muñecas rusas, como matrioshkas, que en su hueco interior esconden otra muñeca más pequeña. La casa de Aída es como una matrioshka, al esconder en su interior una vieja muñeca entre el barro. Del mismo modo, como ya se describió, el cuerpo de Perpetua escondía en su interior el feto de Fausta, que veía en el exterior la vejación padecida por su madre.

De esos cuerpos-envolturas es que el personaje de Magaly Solier tiene que salir para encontrarse consigo misma. ¿De qué manera? Por ejemplo, abriendo la mano para dejar caer las perlas "justicieramente robadas", una vez que se le extrajo en una operación el tubérculo ubicado en su vagina. En otras palabras, lo que se busca es dejar su "concha" libre de las "perlas" para recibir así la presencia masculina, reflejada en el regalo (flores y papas colocadas con composición fálica y testicular en una maceta) que el jardinero le deja en la escena final. La papa como figura vinculada a lo materno se transforma: se abre a lo masculino y a su vez, por eso mismo, se impone como una nueva condición de Fausta en relación con su posición de mujer, que transita del cierre a la apertura. 


\section{La sangre y la leche, el cuerpo y el espíritu}

En el marco de lo que hemos llamado corporalidad vital, es importante detenernos a analizar dos elementos biológicos repetidos durante la película. Por un lado, se habla de la leche y, por el otro, de la sangre. Según el tío de Fausta, es a través de la leche que Perpetua ha pasado a su hija los temores de la violación, los cuales la llevan, como ya se dijo, a colocar en su vagina una papa protectora, un ejemplo que, según ella misma dice, ha tomado de una vecina en la aldea que evitó ser violada por ese medio, y luego pudo casarse y tener hijos. De manera que la leche materna, en lugar de desarrollar su positivo carácter nutricional corporal, se transforma en un elemento nutricional emocional negativo: no alimenta el cuerpo, sino que aterroriza el espíritu; deja de ser un alimento para convertirse en un antialimento. Ese mismo carácter negativo lo encontramos en la sangre nasal que Fausta recurrentemente derrama y le causa constantes desmayos; se trata de una sangre, expresiva, esta vez, de su cuerpo enfermo, tal como la paloma que ella recoge en el gallinero y la lanza al perro; un ave ensangrentada a la cual le dice: “Tú también estás enferma”. Del mismo modo, el tío dice que Fausta "sangra cuando tiene miedo".

Por ello, si Perpetua es un cuerpo-envoltura, Fausta es un cuerpo-cavidad. Este cuerpo, según Fontanille, "proporciona [...] una huella de los órganos y un espacio interior que pueden ocupar, recorrer y modificar los actores (los del gusto, por ejemplo) con su propio movimiento. La percepción de un movimiento semejante es la percepción de una agitación interior" (2008, p. 214). La leche materna, entonces, es un actor semiótico que con su huella dejada bucalmente produce una agitación terrorífica en el interior del cuerpo de Fausta. Ello se expresa a través de la sangre que brota de sus fosas nasales.

Una informante quechua de Theidon cuenta la terrible historia de su sufrimiento y de cómo ello condujo a que le transmitiera la enfermedad, a través de la leche y la sangre, a su hija.

Mi hija nació al día siguiente de la matanza de Lloqllepampa. Estaba escondida en una choza. Le tuve que botar a mi esposo porque si venían los militares le hubieran matado. Solita me atendí. Ese tiempo escondiéndonos, ni siquiera tenía leche para darle a mi bebé. ¿De dónde le iba a dar si no comía? Un día me habían dicho: "Si le dejas a tu hija en el cerro, le puede pachary se puede morir". Recordando eso le dejé en un cerro para que se muera. ¿Cómo ya iba a vivir así? Yo le había pasado todo mi sufrimiento con mi sangre, con mi teta. La veía de lejos, pero como lloraba mucho tenía que regresar a recogerla porque si los soldados escuchaban, hubieran venido a matarme. Es por eso que digo que mi hija está ahora traumatizada por todo que le he pasado con mi leche, con mi sangre, con mis pensamientos. (Mujer quechua hablante. Theidon, 2004, pp. 76-77)

En este testimonio encontramos la confluencia de sangre y leche como medio de transmisión de enfermedad causada por el terror vivido. En La teta asustada, el valor semiótico de estos fluidos se desagrega para reforzar su papel en el estado de Fausta. Aquí, en lugar de un paralelismo que al final se rompe, como el que hemos señalado entre Perpetua y Fausta, encontramos una secuencialidad y complementariedad: leche y sangre se articulan como expresión de dos direcciones corporales. Mientras la leche es el actor semiótico que se introduce en el cuerpo-cavidad de Fausta para enfermar simbólicamente el espíritu, la sangre se manifiesta externamente, se inscribe en la superficie del cuerpo, específicamente en el rostro, para exhibir que dicho cuerpo como tal también está enfermo. 


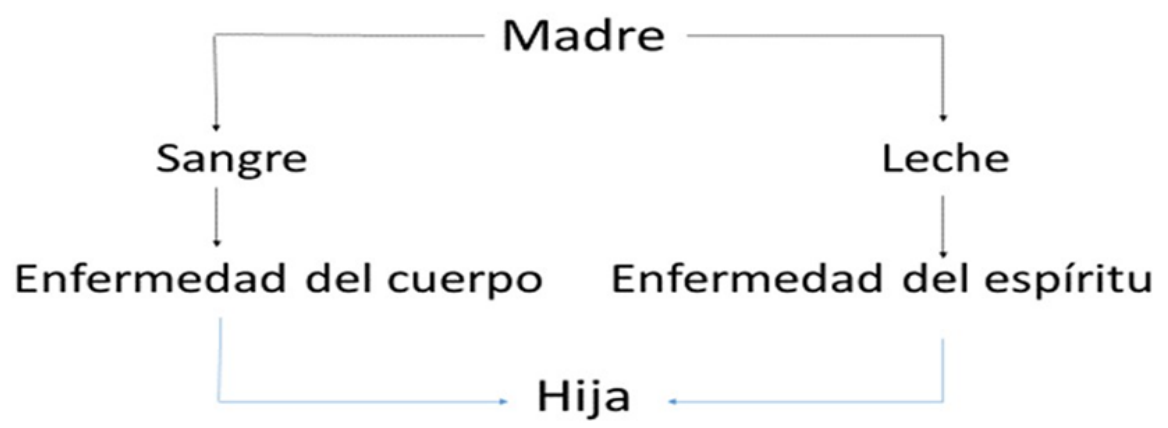

FIGURA 4.

Sangre y leche, cuerpo y espíritu.

Fuente: elaboración propia.

\section{El cuerpo como sitio histórico}

Sin duda el conflicto bélico vivido en Perú durante los años 1980- 2000 ${ }^{[9]}$ marca como un telón de fondo la película de Llosa. Sin ese telón de fondo, la interpretación de la película se vería limitada. Lo interesante es que la directora, sin mencionarlo, proyecta ese sangriento y cruel enfrentamiento en el entramado corporal de sus actores principales, pues ellos guardan en su memoria las cicatrices explícitas del conflicto armado, de las torturas, asesinatos y violaciones. El síndrome de la teta asustada es una consecuencia de las matanzas y violaciones perpetradas, en buena parte, por las Fuerzas Armadas de Perú, destacadas para combatir a los terroristas de la agrupación Sendero Luminoso ${ }^{[10]}$.

En tal sentido, tanto Fausta como Perpetua encarnan en sus cuerpos los recuerdos vivos de sus padecimientos. Justamente, la película se inicia introduciendo ese marco, gracias al triste canto recordatorio de Perpetua. Es por eso que, como dice Theidon, "Las memorias también se sedimentan en nuestros cuerpos, convirtiéndolos en procesos y sitios históricos" (2009, p. 5. Cursivas nuestras); nuestros cuerpos registran la temporalidad y la espacialidad, donde nuestras acciones discurren. Como escenarios de procesos históricos, de vivencias sufridas, los cuerpos, como si estuviesen llenos de tatuajes, acumulan cicatrices abiertas que, en el caso de Perpetua, la acompañarán a lo largo de su recorrido mortuorio. En el caso de Fausta, como hemos mostrado, gracias a la intervención de su tío, quien la exhorta a vivir, y del jardinero, quien la lleva al hospital y simbólicamente la hace florecer, ella logra salir de ese esperado recorrido narrativo mortuorio para realizarse en un recorrido narrativo vital.

Una apreciación similar ha sido hecha por Knoester:

Both the beginning and the ending of the movie bring up an interesting contrast. In both cases we see a close-up of Fausta's face appear from the left of the screen: in the beginning when singing gently to her mother, and in the end to smell the flower of a potato someone left standing in front of her door. In the beginning, she is still inhaling the breath of her background just as her mother is exhaling her last breath, while in the end she is inhaling the fruit of her own struggles. (Knoester, 2010, p. 12)

A pesar de la pesada memoria que arrasa el cuerpo de Perpetua, es ella la que aún la sostenía viva, y le daba fuerzas para vivir a su cuerpo ya inmóvil. Así, cuando Fausta quiere que su madre coma, ella le responde con su canto: "Comeré si me cantas y riegas esta memoria que se seca", y luego agrega: "No veo mis recuerdos, es como si ya no viviera". Inmediatamente muere. En cierto sentido, la muerte no es sino la carencia de recuerdos, la ausencia de memoria, aún si ella incluye evocaciones terribles. 


\section{Conclusiones}

Las semióticas del cuerpo en La teta asustada estructuran el andamiaje simbólico creado por Llosa, guionista y directora, un andamiaje construido paciente y audazmente. Con su película, lanzó una convocatoria, pero también un reto a internarse en los callejones de esta historia provocativa, de una estética desafiante, para descifrar los códigos e interpretar los sentidos de esta historia en la que el discurso fílmico se ancla, firmemente, en la realidad histórica peruana, pero, al mismo tiempo, no le impide volar fuera de esa territorialidad.

Como hemos señalado, las corporalidades desarrolladas a lo largo del film son parte estructural y estructurante de una historia que, si bien se construye inicialmente como un paralelismo entre madre e hija, este se quiebra a partir del entierro de Perpetua, donde se produce una ruptura de la organización espacial, contradictoria, entre costa y sierra, entre lo doméstico y lo urbano y, finalmente, entre el orden telúrico y el marítimo. Ese quiebre espacial es homologable con el del cuerpo de Fausta que, paralelamente, pasa de ser un cuerpo cerrado, negado, silenciado, en clausura, a un cuerpo abierto, afirmado, "florecido".

\section{Referencias}

Agamben, G., y Heller-Roazen, D. (1998). Homo Sacer. Sovereign power and bare life (Trad. D. Heller-Roazen). Stanford University Press.

Álvarez Vita, J. (1990). Diccionario de peruanismos. Studium.

Bachelard, G. (2013). La poética de la ensoñación. Fondo de Cultura Económica.

Bernales Albites, E., y Gómez, L. (2017). Trauma y aislamiento en La teta asustada de Claudia Llosa. Iberoamericana, 17(65), 93-106. https://doi.org/10.18441/ibam.17.2017.65.93-106

Bedoya, R. (2015). El cine peruano en tiempos digitales. Fondo Editorial de la Universidad de Lima.

Bedoya, R., y Cabrejo, J. C. (2009). Los ángulos de La teta asustada. Una entrevista con Claudia Llosa. Ventana Indiscreta, 2, 52-55. https://revistas.ulima.edu.pe/index.php/Ventana_indiscreta/article/view/1678/1672

Branham, W. (s. f.). Un super signe [Artículo en un blog]. http://www.branham.fr/read_propru.php?date=62-0624

Brou, M. (s. f.). Le Super Signe [Artículo en un blog]. http://marxbrou.overblog.com/le-super-signe.html

Cabrejo, J. C. (2009). Posibles claves para entender La teta asustada. Ventana Indiscreta, 2, 46-48. https://www.venta naindiscreta.ulima.edu.pe/post/posibles-claves-para-entender-la-teta-asustada-2009

Chauca, E., Ramírez, R., y Sitnisky-Cole, C. (2010). “No pretendo retratar la realidad. Pretendo interpretar un tema para sacar discusiones que tenemos reprimidas": una entrevista con Claudia Llosa. Mester, 39(1), 45-55. https: //escholarship.org/uc/item/51z578v6

Cirlot, J. E. (1992). Diccionario de simbolos. Editorial Labor.

Comisión de la Verdad y Reconciliación. (2003). Informe Final. Autor. https://www.cverdad.org.pe/ifinal/index.php

Costa, J. (2016). Esquematismo. El universo de la visualización gráfica y la Teoría Informacional del Esquema (3.. parte). http://www.joancostainstitute.com/pdfs/esquematismo_fragmento1.pdf

Di Salvia, D. (2013). La Pachamama en la época incaica y post-incaica:una visión andina a partir de las crónicas peruanas coloniales (siglos XVI y XVII). Revista Española de Antropología Americana, vol. 43, No. 1: 89-110.

Eco, U. (1986). Semiotics and the philosophy of language. Indiana University Press.

Espinoza, D. (2010). Superando la teta asustada: Structural violence, intergenerational trauma, and indigenous Peruvian women's agency. NACCS Annual Conference Proceedings. Paper 5.

Finol, J. E. (2015). La corposfera. antropo-semiótica de las cartografías del cuerpo. Editorial del Centro Internacional de Estudios Superiores de Comunicación para América Latina.

Finol, J. E. (2016). “Tu cuerpo es el mensaje”. La corposfera: cuerpo, ausencia y significación. SituArte, 11(20), 7-18. h ttp://D:/Mis\%20Documentos/Downloads/22339-33211-1-PB.pdf 
Fontanille, J. (2001). Semiótica del discurso. Universidad de Lima.

Fontanille, J. (2008). Soma y sema. Figuras semióticas del cuerpo. Universidad de Lima.

Giacomino, P. (31 de marzo de 2013). Refuerzo semántico. El súper sentido de un signo. El supersigno[Mensaje en un blog]. http://patogiacomino.com/2013/03/31/refuerzo-semantico-el-super-sentido-de-un-signo-el-supersi gno/

Greimas, A. J., y Courtés, J. (1979). Sémiotique. Dictionnaire raisonné de la théorie du langage. Hachette Université.

Knoester, K. (2010). "La Teta Asustada” - an overview. https://es.scribd.com/document/32743298/La-Teta-Asusta da-an-overview

Kristeva, J. (1988). Poderes de la perversión. Siglo XXI.

Laura Atanacio, V. (2015). Feminidades filmadas: Madeinusa (2006) y La teta asustada (2009) entre la tradición y la transgresión (Tesis de maestría). Pontificia Universidad Católica del Perú, Lima.

Lauretis, T. (1996). La tecnología del género (Trad. A. M. Bach \& M. Roulet). Mora, 2, 6-34. https://www.caladona .org/grups/uploads/2012/01/teconologias-del-genero-teresa-de-lauretis.pdf

Leone, M. (2017). Time and Meaning. A Cultural Semiotics of Temporal and Aspectual Ideologies. Lexia. Rivista di semiotica, 27-28: 17-63.

Lillo, G. (2011). La teta asustada (Perú, 2009) de Claudia Llosa: ¿memoria u olvido? Revista de Crítica Literaria Latinoamericana, 37(73), 421-446. https://www.jstor.org/stable/41407246

Llosa, C. (2010). La teta asustada. Guion. Grupo Editorial Norma.

Malvaced, E. (2010). Nakari--formas culturales de sufrimiento tras la violencia política en el Peru. Revista de Investigación en Psicología, 13(2), 129. https://doi.org/10.15381/rinvp.v13i2.3720

Maseda, R. (2014). Habrá cantos sobre oscuros momentos: trauma femenino en La teta asustada de Claudia Llosa. Letras Hispanas, 10(2), 17-33. https://gato-docs.its.txstate.edu/jcr:241da63f-31d1-4ebd-89ee-99f44b694cbc/ 10.2Maseda.pdf

Paredes Dávila, J. (2015). El cine como espacio de representación de una memoria en La teta asustada. TINKUY, 23, 58-73. https://www.academia.edu/17774735/El_cine_como_espacio_de_representaci\%C3\%B3n_de_una_m emoria_en_La_teta_asustada

Rojas, A. (2017). Mother of pearl, song and potatoes: Cultivating resilience in Claudia Llosa’s La teta asustada/Milk of Sorrow. Studies in Spanish \& Latin American Cinemas, 14(3), 297-314. https://doi.org/10.1386/slac.14.3. $297 \_1$

Rueda, C. (2015). Memory, trauma, and phantasmagoria in Claudia Llosa's “La teta asustada”. Hispania, 98(3), 452-462. https://www.jstor.org/stable/i24572691

Sagermann Bustinza, L. (2014). La memoria de la violencia: las consecuencias del conflicto armado contra sendero luminoso representadas en una película y dos novelas peruanas. Studia Romanica Posnaniensia, 41(1), 147-62. h ttps://doi.org/10.14746/strop.2014.411.010

Salinas, P. (2016). El mar en la representación cinematográfica de la migración interna en el Perú: de Gregorio a la teta asustada. Confluencia, 2, 113-127. https://doi.org/10.1353/cnf.2016.0018

Satélite. (11 de febrero de 2018). La Yunza: el carnaval con la fiesta del árbol se celebra en febrero. http://satelite.pe/n oticia/la-yunza-el-carnaval-con-la-fiesta-del-rbol-se-celebra-en-febrero-10247

Tapia, R. (2013). Cuerpo, mirada y género en la película "La teta asustada "de Claudia Llosa. Revista Internacional d'Humanitats, 29, 53-62. https://www.academia.edu/36052944/Cuerpo_mirada_y_g\%C3\%A9nero_en_la_p el\%C3\%ADcula_La_teta_asustada_de_Claudia_Llosa

Theidon, K. (2004). Entre prójimos. El conflicto armado interno y la politica de reconciliación en el Perú. Instituto de Estudios Peruanos.

Theidon, K. (2009). La Teta Asustada: una teoría sobre la violencia de la memoria. Praxis. Un instituto para la justicia social. https://es.scribd.com/document/47926189/La-Teta-Asustada-Theidon

Vallejo, D. (2011). La teta asustada. Ficha técnica. http://www.museodelamujer.org.mx/docs/cineclub/laTetaAsusta da.pdf 
Varas, P. (2012). Posmemoria femenina en "La teta asustada”. Letras Femeninas, 38(1), 31- 41. http://www.jstor.org /stable/23345554

Vela Producciones, Oberón Cinematográfica S. A., \& Wanda Visión S. A. (Producción), \& Llosa, C. (Dirección). (2009). La teta asustada [Película]. Perú- España.

Zilberberg, C. (2016). De las formas de vida a los valores. Universidad de Lima.

\section{Notas}

[1] Título: La teta asustada; Año: 2009; Duración: 95 min.; País: España, Perú, 2005; Idioma: Español, quechua sureño; Directora: Claudia Llosa; Guion: Claudia Llosa; Música: Selma Mutal; Fotografía: Natasha Braier; Productora: Vela Producciones, Wanda Visión S. A., Oberón Cinematográfica S. A.; CONACINE de Perú; Montaje: Frank Gutiérrez; Distribuidora: Wanda Visión S. A.; Reparto: Magaly Solier (Fausta), Susi Sánchez (Aída), Antolín Prieto (Hijo de Aída), Efraín Solís (Noé), Marino Ballón (Tío Lúcido), Bárbara Lazón (Perpetua), María del Pilar Guerrero (Máxima), Delci Heredia (Carmela), Karla Heredia (Severina), Fernando Caycho (Melvin), Edward Llungo (Marcos), Marco Antonio Ramírez (Soldado 3), Doris María Ramírez (Soldado 4). Premios: 2009, Festival Internacional de Cine de Berlín; 2009 , Festival Internacional de Cine de Guadalajara; 2009, Asociación de Críticos de Cine de Québec; 2009, Festival de Lima: 2009, Festival de Cine de Bogotá; 2009, Festival de Cine de la Habana; 2009, Asociación Peruana de Prensa Cinematográfica; 2010, D-World Awards (Vallejo, 2011).

[2] Greimas y Courtés definen la isotopía como "la iteratividad, a lo largo de una cadena sintagmática, de clasemas (= "semas contextuales, recurrentes en el discurso") que aseguran al discurso-enunciado su homogeneidad” (1979, p. 197). Estas últimas "hacen posible la lectura uniforme del discurso, tal como ella resulta de las lecturas parciales de los enunciados que lo constituyen, y de la resolución de sus ambigüedades que es guiada por la búsqueda de una lectura única”. Los autores agregan luego que "en lugar de designar únicamente la iteratividad de clasemas (la isotopía) se define como la recurrencia de categorías sémicas" (1979, p. 197). Eco, por su parte, la define como "un término paraguas que cubre varios fenómenos. Como todo término paraguas esta muestra que la diversidad esconde alguna unidad. En verdad, isotopía se refiere casi siempre a la constancia en una dirección que un texto exhibe cuando es sometido a las reglas de coherencia interpretativa" (1986, p. 201). Eco clasifica las isotopías en discursivas, narrativas y extensionales.

[3] Greimas y Courtés se han referido a la temporalidad como "el efecto de sentido" producido por la temporalización en el proceso de crear la sintaxis discursiva "y transformar así una organización narrativa en 'historia” (1979, p. 388). Leone, por su parte, define la temporalidad como "the product of the encounter between ontological time and language [...] language seeks to construct semiotic artifacts of various kinds whose inner structure resemble that of ontological time, without, for that reason, being in any physical contiguity with it (2017, pp. 18-19). En el marco de la llamada semiótica tensiva, Fontanille refiere un cuerpo propio que define como "una envoltura sensible que determina... un dominio interior y un dominio exterior" (2001, p. 35), que además impone "una orientación, la de la mira (a partir del dominio interno; por consiguiente, en intensidad) y la de la captación (a partir del dominio externo; por consiguiente, en extensión)” (63). Por lo tanto, lo que analizamos a partir de la mira es la energía, y a partir de la captación, el despliegue espacio-temporal (65). Según Zilberberg, el tiempo que es objeto de dicha captación puede abordarse como un rango de duración, entre lo temporalmente menos extenso, lo breve, y lo temporalmente más extenso, lo largo (2016, p. 27).

[4] Utilizamos aquí el verbo incoativo "florecer" para seguir la terminología usada por la propia directora de la película: "La idea de una chica que 'florece' vino antes. Voy trabajando imágenes de una chica que se introduce la papa y que llega a florecer" (Bedoya y Cabrejo, 2009, p. 53).

[5] Di Salvia refiere que la madre tierra andina, conocida como Pachamama, fue objeto de un culto en la época incaica y posincaica $(2013$, p. 89). Además, señala que "no era solo venerada por los pueblos cordilleranos alejados del poder central, sino que también estaba incluida entre las deidades oficiales del panteón incaico, siendo destinataria de un culto estatal y por tanto públicamente notorio" (pp. 90-91). Por ejemplo, Juan Polo de Ondegardo en su crónica Instrucción contra las cerimonias, y ritos que vsan los Indios conforme al tiempo de su infidelidad (1567), que es "cosa comun entre Indios adorar a la tierra fertil, qes la tierra que llaman Pachamama, o Camac pacha, derramando chicha en ella, o coca o otras cosas, para que les haga bien" (di Salvia, 2013, p. 98).

[6] Theidon señala que, según sus informantes, los llakis "constituyen uno de los males centrales, y pueden ser producto tanto de la violencia política como de la pobreza, que sirve como un gatillo para recordar todo lo que uno ha perdido [...] Como cuenta la señora Benedicta, los llakis llenan el corazón, desbordando su capacidad para contener tantos recuerdos dolorosos. Surgen del corazón, llenando el cuerpo: 'eres pura pena”' (2004, pp. 64-65). Otra de sus informantes señala que "-A causa de los llakis que tuvimos cuando se murió mi esposo, de tanto llorar, mis hijos se volvieron locos. Vieron cómo mataban a su papá. Entonces desde ese tiempo se encontraban como en un sueño [muspaypi qina] y se ponían a 
llorar. Con los llakis, no teníamos ganas de comer" (2004, p. 66). Malvaceda ha realizado una descripción de "las distintas formas culturales de vivenciar el sufrimiento tras la violencia política en el Perú" (2010).

[7] Es interesante hacer notar que, así como en La teta asustada Fausta canta a Aída, miembro de una cultura diferente, también Madeinusa, en la película del mismo nombre, canta al fotógrafo extranjero, ajeno a su propia cultura. Valga destacar que ambas películas comienzan con la aparición de personajes que cantan.

[8] El término súper signo ha sido utilizado, con sentidos diferentes al que aquí proponemos, entre otros, por el predicador William Branham (1909-1965), quien lo usaba para referirse a Jesús y al Espíritu Santo: "le super signe de Dieu, un signe éternel [...]. Dieu montre Ses super signes à ceux qui sont nés pour les voir” (s. f.). Otro predicador, Marx Brou, señala que el súper signo "C'est un éternel, signe éternel, Dieu manifesté dans la chair humaine. Dieu Lui-même fait connaître dans la chair humaine" (s. f.). Giacomino llama supersigno a los procesos de "refuerzo semántico" usados en publicidad (2013). También Costa habla de los supersignos como niveles de organización del mensaje: "los "supersignos" (las frases) tienen más poder de contener información y con ello, poseen mayor número de signos y estructuras más complejas [...] Los grafos adquieren sentido cuando se combinan intencionadamente entre sí formando supersignos (esquemas)" (2016, s. p).

[9] Aunque hay varias opiniones sobre la duración del conflicto, nosotros hemos utilizado la señalada por la Comisión de la Verdad y Reconciliación creada en el gobierno de transición del presidente Valentín Paniagua (noviembre de 2000julio de 2001).

[10] "En ciertos periodos y lugares, las Fuerzas Armadas incurrieron en una práctica sistemática o generalizada de la violación de los derechos humanos y [...] existen fundamentos para señalar la comisión de delitos de lesa humanidad, así como infracciones al derecho internacional humanitario" (Comisión de la Verdad y Reconciliación, 2003, 1, 33). Además, "De los casos de violaciones reportados, 83 \% fueron atribuidos a los agentes armados del gobierno" (CVR, 7, 89).

* Artículo de investigación científica. Origen del artículo: El presente artículo recoge los resultados de un proyecto de investigación sobre la famosa película de Claudia Llosa, La teta asustada. Se propone una aproximación novedosa a las articulaciones corporales del sentido en esta premiada película peruana.

\section{Licencia Creative Commons CC BY 4.0}

Para citar este artículo: Finol, J., y Cabrejo, J. (2020). La leche y la sangre, el cuerpo y el espíritu: significaciones de lo corporal en La teta asustada, de Claudia Llosa. Signo y Pensamiento, 39,. https://doi.org/10.11144/ Javeriana.syp39.1sce 